\title{
Analytic Approach to Alloys Thermodynamics: Ternary Cu-Ga-Ni system
}

\author{
Lidija Gomidželovića *, Ana Kostov ${ }^{a}$, Dragana Živkovićb, Vesna Krstic ${ }^{a}$ \\ ${ }^{a}$ Mining and Metallurgy Institute Bor, Zeleni bulevar, 35, 19210, Bor, Serbia \\ ${ }^{b}$ University of Belgrade, Technical Faculty, VJ 12, 19210, Bor, Serbia
}

Received: April 23, 2015; Revised: December 2, 2015; Accepted: July 13, 2016

\begin{abstract}
In this paper are presented the results of the calculation of thermodynamic properties in liquid state for ternary $\mathrm{Cu}-\mathrm{Ga}-\mathrm{Ni}$ alloys using the newest version of general solution model. Calculation was carried out in temperature interval 1473-2073 K, along 3 cross sections from corner of each metal, with ratios between two other metals 1:3, 1:1 and 3:1. Partial and integral molar thermodynamic properties in liquid phase for the $\mathrm{Cu}-\mathrm{Ga}-\mathrm{Ni}$ ternary system are determined, presented and discussed. Calculated data is compared with data available from literature and good agreement between these two sets of data was observed. Additionally, isothermal section of phase diagram at $298 \mathrm{~K}$ is calculated using Thermo-Calc software and presence of eleven different phases is detected. Presented thermodynamic data for the $\mathrm{Cu}-\mathrm{Ga}-\mathrm{Ni}$ alloys could be useful for the further assessment of this system and its phase diagram as well as for completing thermodynamic description of these alloys.
\end{abstract}

Keywords: Ternary Cu-Ga-Ni system, Thermodynamics, Calculation, General solution model

\section{Introduction}

Thermodynamic properties have always held an important place in the study of metallic systems. In the past, thermodynamic quantities mainly have been studied experimentally, but researchers have sought a way to develop different models that would enable calculation of the thermodynamic properties of studied systems, which would not only significantly lower experimental research expenses, but also speed up the research process. For calculation of thermodynamic properties of multicomponent systems different geometric models have been developed, such as Toop ${ }^{1}$, Muggianu ${ }^{2}$, general solution model ${ }^{3-5}$ etc.

Among available models, general solution model developed by $\mathrm{Chou}^{3,4}$ has been proved to be most reasonable one in all aspects. This geometric model has been successfully used by different researchers for calculation of thermodynamic properties $^{6-10}$, construction and/or evaluation of phase diagrams ${ }^{11-13}$, computing physicochemical properties ${ }^{14-16}$ and solving technical problems ${ }^{17-20}$. In 2010 Zhang and $\mathrm{Chou}^{5}$ published new, improved version of general solution model for calculation of thermodynamic properties of liquid mixtures, based on binary Redlich-Kister type parameters and this version has been used to predict thermodynamic properties of metallic systems in liquid phase ${ }^{21}$.

Ternary $\mathrm{Cu}-\mathrm{Ga}-\mathrm{Ni}$ system has great technical and theoretical significance because:

- copper, gallium and nickel are elements included in developing different high temperature lead free solder materials ${ }^{22}$,

- $\quad$ presence of $\mathrm{Cu}-\mathrm{Ga}-\mathrm{Ni}$ alloy is detected during study of $\mathrm{Pb}$-free joints produced by using a diffusion soldering method $^{23}$,
- this type of alloys are used to develop new microelectronic interconnect materials ${ }^{24}$ and

- these alloys are basis for forming different multicomponent shape memory alloys like $\mathrm{Ni}-\mathrm{Cu}$ $\mathrm{Mn}-\mathrm{Ga}^{25,26}$ and Ni-Mn-Fe-Cu-Ga ${ }^{27}$.

Despite all of these facts, there is considerable lack of available data on thermodynamic properties of ternary $\mathrm{Cu}-\mathrm{Ga}-\mathrm{Ni}$ alloys in literature (there is just one recent paper dealing with this topic ${ }^{28}$ ), although that type of data is essential in further research of phase diagram and understanding of complex processes which occur during bonding and soldering with gallium based materials. Accordingly, the aim of this work is to conduct thermodynamic analysis of ternary $\mathrm{Cu}-\mathrm{Ga}-\mathrm{Ni}$ system using general solution model.

\section{Theoretical fundamentals}

Among many available methods for calculation thermodynamic properties of ternary system based on information about constitutive binary systems, Chou's general solution model (GSM) ${ }^{3}$ has been proved to be most reasonable one in all aspects, overcoming inherent defects of the traditional symmetrical and asymmetrical geometric models. This model breaks down boundaries between symmetrical and asymmetrical systems and generalizes various kinds of situations; also accuracy of calculation has been proven in practical examples ${ }^{29-32}$.

Recently, a new, improved version of general solution model based on Redlich-Kister parameters was presented by Zhang and $\mathrm{Chou}^{5}$. Since older version of GSM involved a series of integration processes which significantly complicated calculation and considering that a large number of real systems 
can be approximately fit through a Redlich-Kister polynomial, a new formalism, based on the binary Redlich-Kister type parameters, was presented.

Therefore, this new GSM version is utilized for calculating the thermodynamic properties of $\mathrm{Cu}-\mathrm{Ga}-\mathrm{Ni}$ ternary system.

The basic equation of general solution model for ternary system is:

$$
\begin{aligned}
& \Delta G^{E}=\chi_{1} \chi_{2} \sum_{i=0}^{n} L_{12}^{i}\left(\chi_{1}-\chi_{2}+\left(2 \xi_{12}-1\right) \chi_{3}\right)^{i}+ \\
& \chi_{2} \chi_{3} \sum_{i=0}^{n} L_{23}^{i}\left(\chi_{2}-\chi_{3}+\left(2 \xi_{23}-1\right) \chi_{1}\right)^{i}+ \\
& \chi_{3} \chi_{1} \sum_{i=0}^{n} L_{31}^{i}\left(\chi_{3}-\chi_{1}+\left(2 \xi_{31}-1\right) \chi_{2}\right)^{i}
\end{aligned}
$$

where $L_{i j}^{v}$ are the Redlich-Kister parameters for the binary system $i j$, independent from composition and only relying on temperature; $\Delta G^{E}$ is integral molar excess Gibbs energy for ternary system and $x_{i}$ is mole fraction of the component $i$.

Similarity coefficient $\xi$ is defined as:

$$
\begin{aligned}
& \xi_{12}=\eta_{I} /\left(\eta_{I}+\eta_{I I}\right) \\
& \xi_{23}=\eta_{I I} /\left(\eta_{I I}+\eta_{I I I}\right) \\
& \xi_{31}=\eta_{I I I} /\left(\eta_{I}+\eta_{I I}\right)
\end{aligned}
$$

And the deviation sum of squares can be calculated using:

$$
\begin{aligned}
& \eta_{I}=\sum_{i=0}^{n} \frac{1}{2(2 i+1)(2 i+3)(2 i+5)}\left(L_{12}^{i}-L_{13}^{i}\right)^{2}+ \\
& \sum_{j=0}^{n} \sum_{k>j}^{n} \frac{1}{(j+k+1)(j+k+3)(j+k+5)}\left(L_{12}^{j}-L_{13}^{j}\right)\left(L_{12}^{k}-L_{13}^{k}\right) \\
& \eta_{I I}=\sum_{i=0}^{n} \frac{1}{2(2 i+1)(2 i+3)(2 i+5)}\left(L_{21}^{i}-L_{23}^{i}\right)^{2}+ \\
& \sum_{j=0}^{n} \sum_{k>j}^{n} \frac{1}{(j+k+1)(j+k+3)(j+k+5)}\left(L_{21}^{j}-L_{23}^{j}\right)\left(L_{21}^{k}-L_{23}^{k}\right) \\
& \eta_{I I I}=\sum_{i=0}^{n} \frac{1}{2(2 i+1)(2 i+3)(2 i+5)}\left(L_{31}^{i}-L_{32}^{i}\right)^{2}+ \\
& \sum_{j=0}^{n} \sum_{k>j}^{n} \frac{1}{(j+k+1)(j+k+3)(j+k+5)}\left(L_{31}^{j}-L_{32}^{j}\right)\left(L_{31}^{k}-L_{32}^{k}\right)
\end{aligned}
$$

where for all $L_{i j}$ parameters is valid relation $L_{i j}^{k}=(-1)^{k} L_{j i}^{k}$. In all equations as given, $L_{i j}^{x}(x=i, j$ or $k)$ are the RedlichKister parameters for the binary system $i j$, independent from composition and only relying on temperature; $\Delta G^{\mathrm{E}}$ is integral molar excess Gibbs energy for ternary system and $x_{i}$ is mole fraction of the component $i$. Number $\mathrm{n}$ is equal to maximum number of components in system (in this case $n=3$ ) and coefficients $\mathrm{i}, \mathrm{j}$ and $\mathrm{k}$ are always numbers between zero and $\mathrm{n}$.

Partial thermodynamic quantities are calculated according to the equations:

$$
G_{i}^{E}=G^{E}+\left(1-\chi_{i}\right)\left(\partial G^{E} / \partial \chi_{i}\right)=R T \ln \gamma_{i}
$$

and

$$
a_{i}=\chi_{i} \gamma_{i}
$$

In above mentioned equations $G^{E}{ }_{i}$ is partial molar excess Gibbs energy of component $i, \mathrm{a}_{i}$ is activity of component $i$, $\gamma_{i}$ is activity coefficient of component $i, T$ is temperature, $R$ is gas constant (value $8.314 \mathrm{JK}^{-1} \mathrm{~mol}^{-1}$ ), $G^{E}$ is Gibbs energy for whole system, dependent on composition.

\section{Results and discussion}

Basic thermodynamic data on the constituent binary subsystems $\mathrm{Cu}-\mathrm{Ga}$, Ga-Ni and $\mathrm{Cu}-\mathrm{Ni}$, needed for calculation of thermodynamic properties in the investigated $\mathrm{Cu}-\mathrm{Ga}-\mathrm{Ni}$ system, were taken from available literature data $\mathrm{a}^{33-35}$, and presented in the form of Redlich-Kister parameters in Table 1.

Thermodynamic properties of ternary $\mathrm{Cu}-\mathrm{Ga}-\mathrm{Ni}$ system has been investigated in 9 sections (Figure 1), taken from $\mathrm{Cu}, \mathrm{Ga}$ and Ni corner, respectively, with ratios 1:3 and 3:1, and with molar content of 0-0.9 for the third component.

The calculated integral molar Gibbs excess energies $\left(\Delta G^{E}\right)$ and activities of the investigated system $\mathrm{Cu}-\mathrm{Ga}-\mathrm{Ni}$, along selected sections and at given temperatures, are presented in Figures 2 - 4. All thermodynamic properties calculated in this work are related to the liquid phase.

Calculation of thermodynamic properties for ternary system $\mathrm{Cu}-\mathrm{Ga}-\mathrm{Ni}$ was performed using the general solution model. Excess integral Gibbs energy values for investigated sections from nickel corner are negative, with minimum values up to $-14 \mathrm{~kJ} / \mathrm{mol}$, for gallium corner those values are between $4 \mathrm{~kJ} / \mathrm{mol}$ and $-14 \mathrm{~kJ} / \mathrm{mol}$, while for the investigated section from the corner of copper Gibbs energy is within 0 $\mathrm{kJ} / \mathrm{mol}$ to $-18 \mathrm{~kJ} / \mathrm{mol}$.

For cross section $\mathrm{Ga}: \mathrm{Ni}=1: 3$ copper activity shows positive deviation from Rault's law which with increase of copper content in alloy slowly decreases and for $\mathrm{x}_{\mathrm{Cu}}>0.6$ coincides with the ideal state line. Other investigated cross sections from copper corner shows variable character of deviation from Rault's law, in section $\mathrm{Ga}: \mathrm{Ni}=1: 1$ copper activity has positive deviation up to $\mathrm{x}_{\mathrm{Cu}}=0.4$, and for $\mathrm{Ga}: \mathrm{Ni}=3: 1$ border copper content at which deviation changing from positive to negative occurs is $\mathrm{x}_{\mathrm{Cu}}=0.2$.

For gallium activity is characteristic pronounced negative deviation from Rault's law for all investigated sections, but for alloys with high gallium content $\left(\mathrm{x}_{\mathrm{Ga}}>0.9\right)$ deviation coincides with the line of ideal state and even becomes slightly positive.

Nickel activity shows a negative deviation from the Rault's law for $\mathrm{Cu}: \mathrm{Ga}=1: 3$ and $\mathrm{Cu}: \mathrm{Ga}=1: 1$ sections, up to $\mathrm{x}_{\mathrm{Ni}}>0.8$, while for section $\mathrm{Cu}: \mathrm{Ga}=3: 1$ nickel activities positively derivate from ideal state line.

Because of notable absence of experimental data related to thermodynamics of this system in literature, data obtained by calculation are compared with data obtained using Redlich-Kister-Muggianu (RKM) model $^{28}$ (Figure 5). Compared values show very good agreement. 
Table 1: Redlich-Kister parameters for constitutive binary systems (in $\mathrm{J} / \mathrm{mol}$ )

\begin{tabular}{lccc}
\hline System $i j$ & $\mathrm{~L}_{\mathrm{ij}}^{0}(\mathrm{~T})$ & $\mathrm{L}_{\mathrm{ij}}^{1}(\mathrm{~T})$ & $\mathrm{L}_{\mathrm{ij}}^{2}(\mathrm{~T})$ \\
\hline${\mathrm{Cu}-\mathrm{Ga}^{33}}^{33}$ & $-58110.5+154.5439 * \mathrm{~T}-18.3753 * \mathrm{~T} * \ln \mathrm{T}$ & $-33884.7+1.9151 * \mathrm{~T}$ & -11256.9 \\
$\mathrm{Ga}^{-N i}{ }^{34}$ & $-122488.59+35.72 * \mathrm{~T}$ & $-29685+14 * \mathrm{~T}$ & $-30751.9+22.1 * \mathrm{~T}$ \\
$\mathrm{Cu}^{35}{ }^{35}$ & $12048.61+1.29893 * \mathrm{~T}$ & $-1861.61+0.94201 * \mathrm{~T}$ & 0 \\
\hline
\end{tabular}

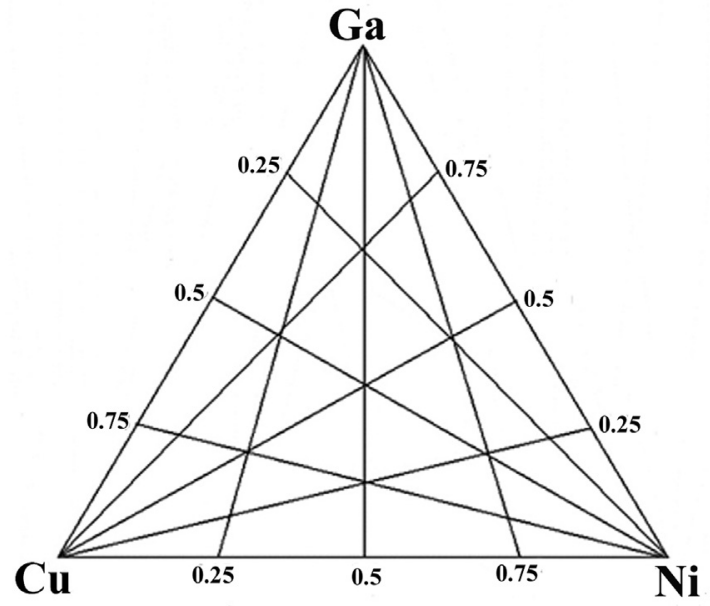

Figure 1: Schematic diagram of the investigated concentration regions in ternary $\mathrm{Cu}-\mathrm{Ga}-\mathrm{Ni}$ system.
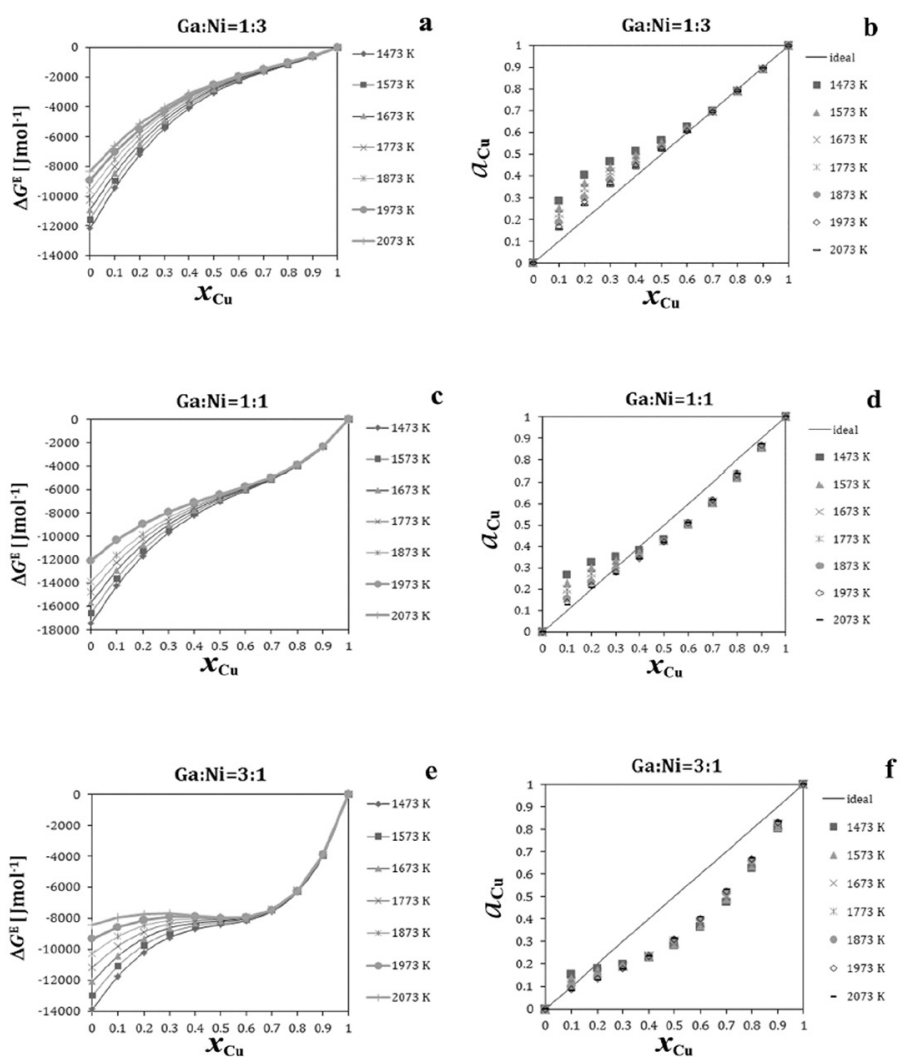

Figure 2: Results of thermodynamic calculation according to GSM in temperature range of 1473-2073K for cross-sections from copper corner: a) integral molar excess Gibbs energy $\left(\Delta \mathrm{G}^{\mathrm{E}}\right)$ and b) copper activity for cross section $\left.\mathrm{Ga}: \mathrm{Ni}=1: 3 ; \mathrm{c}\right) \Delta G^{\mathrm{E}}$ and d) copper activity for cross section $\mathrm{Ga}: \mathrm{Ni}=1: 1$; e) $\Delta G^{\mathrm{E}}$ and f) copper activity for cross section $\mathrm{Ga}: \mathrm{Ni}=3: 1$. 

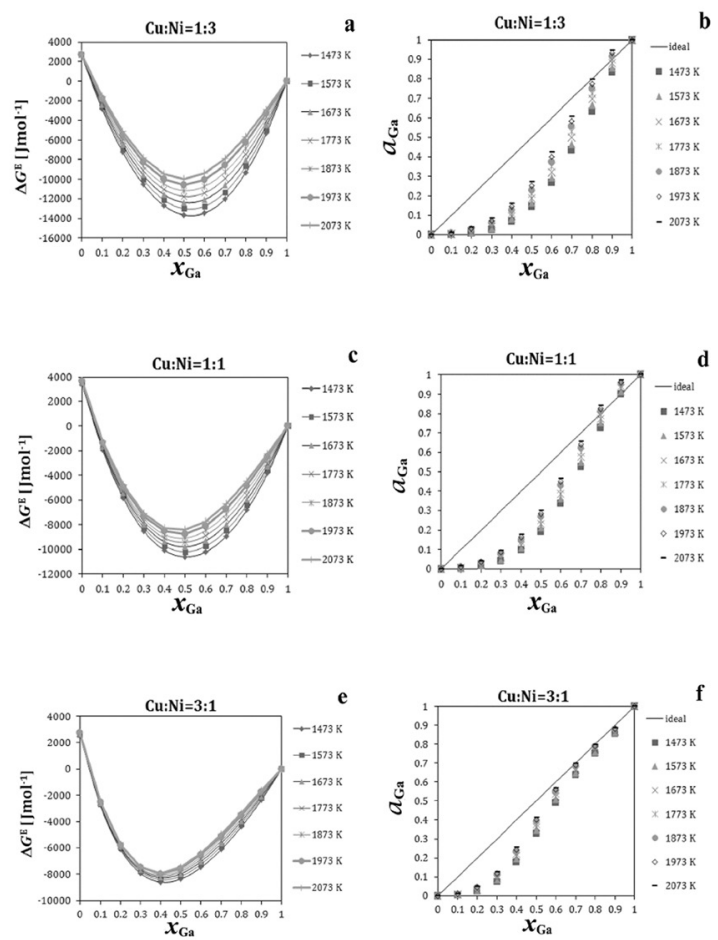

Figure 3: Results of thermodynamic calculation according to GSM in temperature range of 1473-2073K for cross-sections from gallium corner: a) integral molar excess Gibbs energy $\left(\Delta \mathrm{G}^{\mathrm{E}}\right)$ and b) gallium activity for cross section $\mathrm{Cu}: \mathrm{Ni}=1: 3$; c) $\Delta G^{\mathrm{E}}$ and d) gallium activity for cross section $\mathrm{Cu}: \mathrm{Ni}=1: 1$; e) $\Delta G^{\mathrm{E}}$ and f) gallium activity for cross section $\mathrm{Cu}: \mathrm{Ni}=3: 1$.
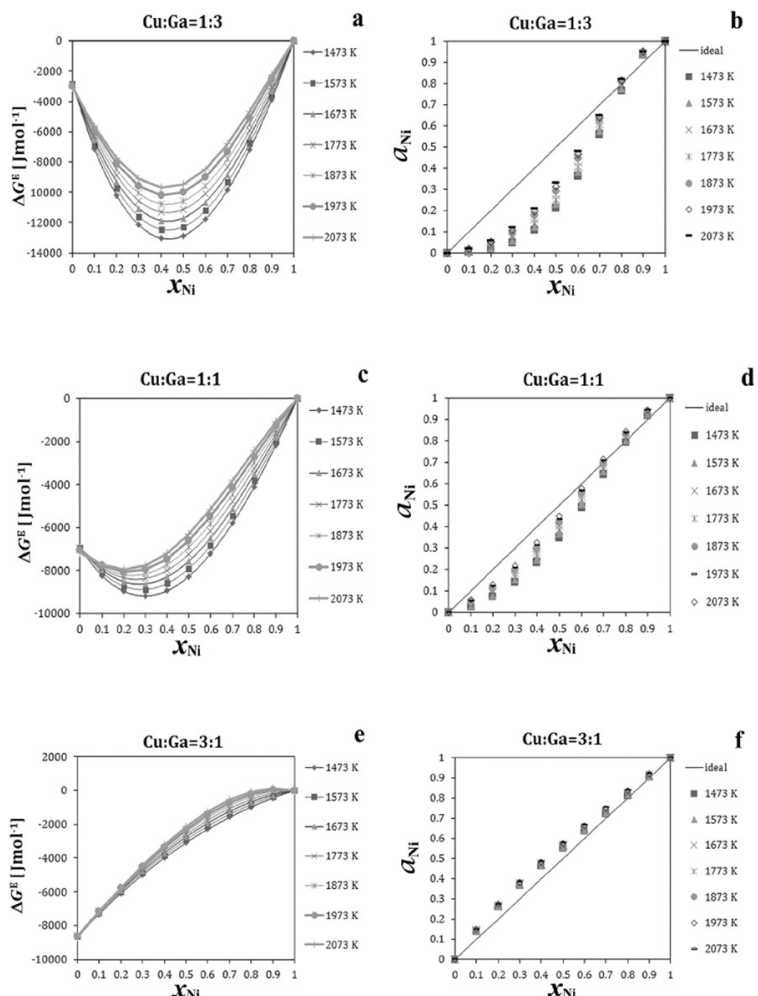

Figure 4: Results of thermodynamic calculation according to GSM in temperature range of 1473-2073K for cross-sections from nickel corner: a) integral molar excess Gibbs energy $\left(\Delta \mathrm{G}^{\mathrm{E}}\right)$ and b) nickel activity for cross section $\left.\mathrm{Cu}: \mathrm{Ga}=1: 3 ; \mathrm{c}\right) \Delta G^{\mathrm{E}}$ and d) nickel activity for cross section $\mathrm{Cu}: \mathrm{Ga}=1: 1$; e) $\Delta G^{\mathrm{E}}$ and f) nickel activity for cross section $\mathrm{Cu}: \mathrm{Ga}=3: 1$. 

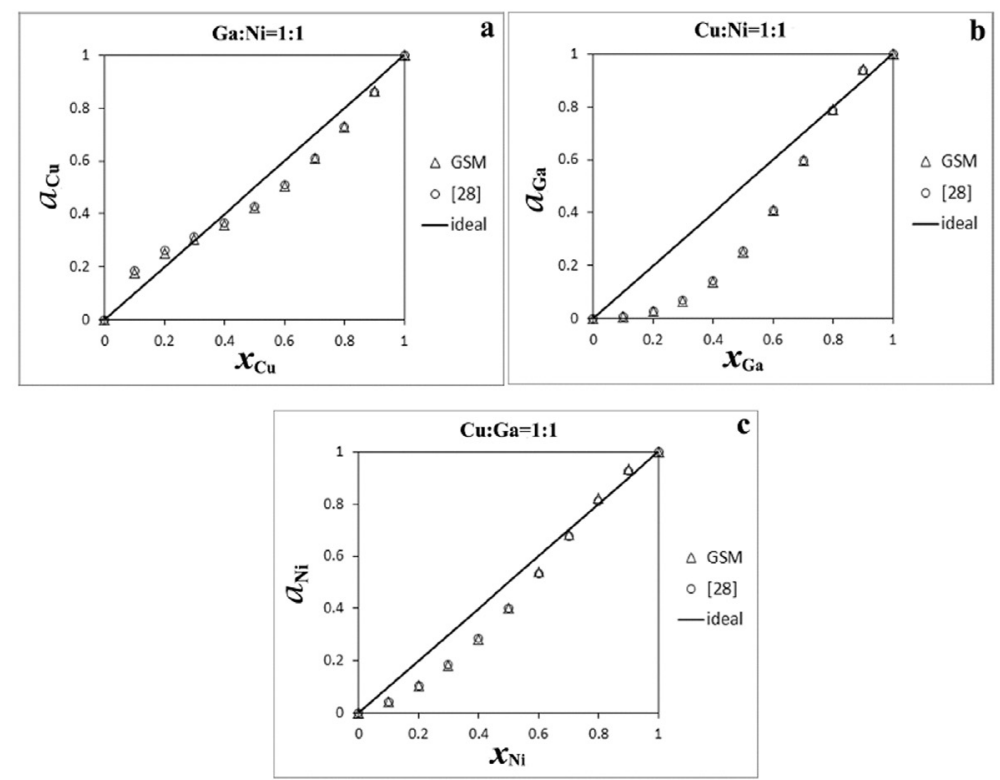

Figure 5: Dependence of copper (a), gallium (b) and nickel (c) activities from composition at $1773 \mathrm{~K}$, predicted according to GSM, compared with literature data ${ }^{28}$.

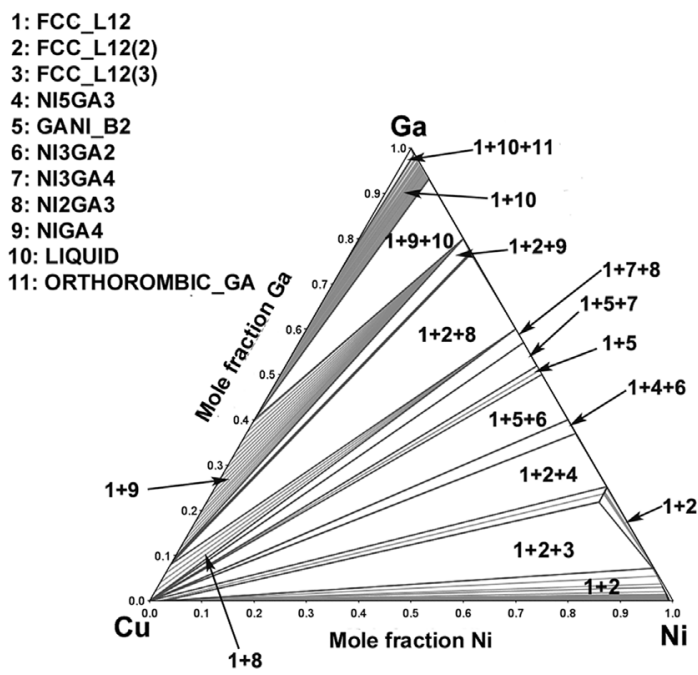

Figure 6: Calculated isothermal section of ternary $\mathrm{Cu}-\mathrm{Ga}-\mathrm{Ni}$ phase diagram at $298 \mathrm{~K}$ (obtained using Thermocalc 3.0).

them are intermetallic compounds present in phase diagram of binary Ga-Ni binary system ${ }^{40}$. Phase 1 is consisted from nickel with some gallium and copper (due to mutual solubility), phase 2 from copper with little amount of nickel, and phase 3 is pure gallium. It is not surprising to detect liquid phase at room temperature, considering that melting temperature of gallium is just $29.78^{\circ} \mathrm{C}(302.93 \mathrm{~K})^{41}$.

\section{Conclusion}

Calculation of thermodynamic properties of the $\mathrm{Cu}-\mathrm{Ga}$ Ni system has been conducted using general solution model, in temperature interval from 1473 to $2073 \mathrm{~K}$.
Based on this, excess molar Gibbs energies and activity of all components were calculated. Calculated excess integral Gibbs energy for investigated sections is mostly negative, with values in range from $4 \mathrm{~kJ} / \mathrm{mol}$ to $-18 \mathrm{~kJ} / \mathrm{mol}$. Activity of nickel and gallium shows negative deviation from Rault's law for all investigated sections, but for alloys with high content of nickel or gallium, deviation becomes slightly positive. Deviation of copper activity values from Rault's law depends from share of two other metals, and for alloy which contain same amount of nickel and gallium $(\mathrm{Ga}: \mathrm{Ni}=1: 1)$ copper activity negatively deviates from ideal conditions after $\mathrm{x}_{\mathrm{Cu}}=0.4$.

Isothermal section of ternary $\mathrm{Cu}-\mathrm{Ga}-\mathrm{Ni}$ phase diagram at $298 \mathrm{~K}$ is calculated using Thermo-Calc software, based on thermodynamic data which is supplied in a database SSOL5 and presence of eleven different phases is detected.

Presented thermodynamic data for the $\mathrm{Cu}-\mathrm{Ga}-\mathrm{Ni}$ alloys could be useful for the further assessment of this system and its phase diagram as well as for completing thermodynamic description of these alloys.

\section{Acknowledgement}

The authors are grateful to the Ministry of Education, Science and Technological Development of the Republic of Serbia, Projects 34005: "Development of ecological knowledge-based advanced materials and technologies for multifunctional application" and 172037 "Modern multi-component metal systems and nanostructured materials with different functional properties", for financial support. 


\section{References}

1. Toop GW. Predicting ternary activities using binary data. Transactions of Metallurgical Society of AIME. 1965;233:850-854.

2. Muggianu YM, Gambino M, Bross JP. Enthalpies of formation of liquid alloys bismuth-gallium-tin at $723 \mathrm{k}$. Choice of an analytical representation of integral and partial thermodynamic functions of mixing for this ternary-system. Journal de Chimie Physique et de Physico-Chimie Biologique. 1975;72(1):83-88.

3. Chou KC. A general solution model for predicting ternary thermodynamic properties. Calphad. 1995;19(3):315-325.

4. Chou KC, Wei SK. A new generation solution model for predicting thermodynamic properties of a multicomponent system from binaries. Metallurgical and Materials Transactions $B$. 1997;28(3):439-445.

5. Zhang GH, Chou KC. General formalism for new generation geometrical model: application to the thermodynamics of liquid mixtures. Journal of Solution Chemistry. 2010;39(8):1200-1212.

6. Trumić B, Zivković D, Živković Ž, Manasijević D. Comparative thermodynamic analysis of the $\mathrm{Pb}-\mathrm{Au}_{0.7} \mathrm{Sn}_{0.3}$ section in the $\mathrm{Pb}-\mathrm{Au}-$ Sn ternary system. Thermochimica Acta. 2005;435(1):113-117.

7. Živković D, Živković Ž, Tasić I. Comparative thermodynamic study of the $\mathrm{Pb}-\mathrm{Bi}_{2} \mathrm{Mg}_{3}$ system. Thermochimica Acta. 2000;362(12):113-120.

8. Manasijević D, Živković D, Živković Ž. Prediction of the thermodynamic properties for the Ga-Sb-Pb ternary system. Calphad. 2003;27(4):361-366.

9. Minić D, Živković D, Živković Ž. Thermodynamic and structural analysis of the $\mathrm{Pb}-\mathrm{InSb}$ system. Thermochimica Acta. 2003;400(1-2):143-152.

10. Živković D, Živković Ž, Vučinić B. Comparative thermodynamic analysis of the $\mathrm{Bi}_{-} \mathrm{Ga}_{0.1} \mathrm{Sb}_{0.9}$ section in the $\mathrm{Bi}-\mathrm{Ga}-\mathrm{Sb}$ system. Journal of Thermal Analysis and Calorimetry. 2000;61(1):263-271.

11. Wan JF, Chen SP, Hsu TY. The stability of transition phases in Fe-Mn-Si based alloys. Calphad. 2001;25(3):355-362.

12. Jin XJ, Dunne D, Allen SM, O’Handley RC, Hsu TY. Thermodynamic consideration of the effect of alloying elements on martensitic transformation in Fe-Mn-Si based alloys. Journal de Physique IV France. 2003;112:369-372.

13. Liu YJ, Liang D. A contribution to the Al-Pb-Zn ternary system. Journal of Alloys and Compounds. 2005;403(1-2):110-117.

14. Wang LJ, Chou KC, Seetharaman S. A comparison of traditional geometrical models and mass triangle model in calculating the surface tensions of ternary sulphide melts. Calphad. 2008;32(1):49-55.

15. Prasad LC, Mikula A. Surface segregation and surface tension in Al-Sn-Zn liquid alloys. Physica B: Condensed Matter. 2006;373(1):142-149.

16. Yan LJ, Zheng SB, Ding GJ, Xu GT, Qiao ZY. Surface tension calculation of the Sn-Ga-In ternary alloy. Calphad. 2007;31(1):112-119.

17. Sun ZB, Guo J, Li Y, Zhu YM, Li Q, Song XP. Effects of Ti addition on the liquid-phase separation of $\mathrm{Cu}_{71} \mathrm{Cr}_{29}$ alloy during rapid cooling. Metallurgical and Materials Transactions A. 2008;39(5):1054-1059.
18. Prasad LC, Mikula A. Thermodynamics of liquid Al-Sn-Zn alloys and concerned binaries in the light of soldering characteristics. Physica B: Condensed Matter. 2006;373(1):64-71.

19. Gao F, Takemoto T, Nishikawa H, Komatsu A. Microstructure and mechanical properties evolution of intermetallics between $\mathrm{Cu}$ and $\mathrm{Sn}-{ }_{35} \mathrm{Ag}$ solder doped by Ni-Co additives. Journal of Electronic Materials. 2006;35(5):905-911.

20. Ma X, Yoshida F. Interaction relation in $60 \mathrm{Sn}-\mathrm{Pb}-0.05 \mathrm{La}$ ternary solder alloy. Materials Letters. 2002;56(4):441-445.

21. Živković D, Du Y, Talijan N, Kostov A, Balanović L. Calculation of thermodynamic properties in liquid phase for ternary Al$\mathrm{Ni}-\mathrm{Zn}$ alloys. Transactions of Nonferrous Metals Society of China. 2012;22(12):3059-3065.

22. Kroupa A, Dinsdale A, Watson A, Vreštal JJ, Zemanova A, Broz P. The thermodynamic database COST MP0602 for materials for high-temperature lead-free soldering. Journal of Mining and Metallurgy. Section B: Metallurgy. 2012;48(3):339-346.

23. Sommadossi S, Troiani HE, Fernández-Guillermet A. Diffusion soldering using a Gallium metallic paste as solder alloy: study of the phase formation systematics. Journal of Materials Science. 2007;42:9707-9712.

24. Baldwin DF, Deshmukh RD, Hau CS. Gallium alloy interconnects for flip-chip assembly applications. IEEE Transactions on Components and Packaging Technologies. 2000;23(2):360-366.

25. Wang J, Li P, Jiang C. Phase stability and magnetic properties of $\mathrm{Ni}_{50-\mathrm{x}} \mathrm{Cu}_{\mathrm{x}} \mathrm{Mn}_{31} \mathrm{Ga}_{19}$ alloys. Intermetallics. 2013;34:14-17.

26. Li Y, Wang J, Jiang C. Study of Ni-Mn-Ga-Cu as single-phase wide-hysteresis shape memory alloys. Materials Science and Engineering: A. 2011;528(22-23):6907-6911.

27. Khan M, Gautam B, Pathak A, Dubenko I, Stadler S, Ali S. Intermartensitic transitions in $\mathrm{Ni}-\mathrm{Mn}-\mathrm{Fe}-\mathrm{Cu}-\mathrm{Ga}$ Heusler alloys. Journal of Physics: Condensed Matter. 2008;20(50):505206.

28. Gomidželović L, Požega E, Kostov A, Krstić V. Thermodynamic analisys of $\mathrm{Cu}-\mathrm{Ga}-\mathrm{Ni}$ system using RKM model. Copper. 2014;39(1):1-8. (in Serbian).

29. Balanović L, Živković D, Mitovski A, Manasijević D, Živković Ž. Calorimetric investigations and thermodynamic calculation of Zn-Al-Ga system. Journal of Thermal Analysis and Calorimetry. 2011;103(3):1055-1061.

30. Gomidželović L, Mihajlović I, Kostov A, Živković D. Cu-Al-Zn System: Calculation of thermodynamic properties in liquid phase. Hemijska industrija. 2013;67(1):157-164.

31. Živković D, Minić D, Manasijević D, Kostov A, Talijan N, Balanović L, et al. Thermodynamic analysis and characterization of alloys in Bi-Cu-Sb system. Journal of Mining and Metallurgy. Section B: Metallurgy. 2010;46(1):105-111.

32. Živković D, Holjevac Grgurić T, Gojić M, Čubela D, Stanojević Šimišić Z, Kostov A, et al. Calculation of Thermodynamic Properties of $\mathrm{Cu}-\mathrm{Al}-(\mathrm{Ag}, \mathrm{Au})$ Shape Memory Alloy Systems. Transactions of the Indian Institute of Metals. 2014;67(2):285-289.

33. Li JB, Ji LN, Liang JK, Zhang Y, Luo J, Li CR, et al. A thermodynamic assessment of the copper-gallium system. Calphad. 2008;32(2):447-453. 
34. Yuan WY, Qiao ZY, Ipser H, Eriksson G. Thermodynamic assessment of the Ni-Ga system. Journal of Phase Equilibria and Diffusion. 2004;25(1):68-74.

35. an May S. Thermodynamic re-evaluation of the $\mathrm{Cu}-\mathrm{Ni}$ system. Calphad. 1992;16(3):255-260.

36. Andersson JO, Helander T, Höglund L, Shi P, Sundman B. Thermo-Calc \& DICTRA, computational tools for materials science. Calphad. 2002;26(2):273-312.

37. Thermo-Calc Software. Available from: $<\mathrm{http}: / / \mathrm{www}$.thermocalc. com>. Access in: 27/7/2016.
38. Lukas H, Fries SG, Sundman B. Computational Thermodynamics: The Calphad Method. New York: Cambridge University Press; 2007.

39. CALPHAD. Available from: $<$ http://www.calphad.org $>$. Access in: $27 / 7 / 2016$

40. FactSage 7.0. Available from: $<$ http://www.factsage.cn $>$. Access in: $27 / 7 / 2016$

41. Galium. Chemichal Elements.com. Available from: <http:// www.chemicalelements.com/elements/ga.html>. Access in: 27/7/2016. 